\title{
ALGUNAS INTERPRETACIONES DE LA FILOSOFÍA DE WITTGENSTEIN
}

\section{INTERPRETATIONS OF WITTGENSTEIN PHILOSOPHY}

\author{
Yors Solís \\ Universidad Nacional de Costa Rica
}

Recibido: 5 de febrero, 2014 Aceptado: 18 noviembre, 2015

Resumen: El siguiente artículo expone y analiza algunas de las interpretaciones más discutidas y destacadas que se han realizado sobre la filosofía wittgensteiniana. No sin antes dejar claro que para el mismo Wittgenstein este trabajo y los que analizaré no hubieran tenido sentido.

Palabras clave: Wittgenstein, filosofía wittgensteiniana, interpretaciones

Abstract: The following article presents and analyzes some of the most controversial and prominent interpretations that have been made about Wittgenstein's philosophy. Not before without clarifying that for Wittgenstein himself, this work and the ones that will be discussed, would be senseless for him.

Keywords: Wittgenstein, Wittgenstein Philosophy, interpretations

\section{Nota importante sobre la filosofía de Wittgenstein}

Antes de iniciar este artículo es importante traer a colación la nota 128 de las Investigaciones filosóficas: «Si se quisiera proponer tesis en filosofía, nunca se podría llegar a discutirlas porque todos estarían de acuerdo con ellas» (Wittgenstein 1988)1.

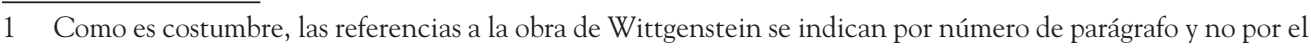
número de página del texto. 
Si decidiera apegarme sensu stricto a la filosofía de Wittgenstein, este trabajo y las interpretaciones que analizaré seguidamente no deberían haberse escrito, pues para el mismo Wittgenstein — ya sea el del Tractatus logico-philosophicus (1999), quien consideraba su libro como una especie de preparación para la actividad lógico-analítica del filosofar, o el de las Investigaciones filosóficas (1988), para quien, como lo dijo expresamente en la nota 128, no tiene sentido escribir tesis en filosofía - serían inútiles y poco o nada filosóficos, ya que serían considerados por este autor como unas «vacaciones» del lenguaje, pues la filosofía para Wittgenstein no propone ni discute tesis ni discursos ni especulaciones teóricas, sino que analiza lógicamente (Tractatus logico-philosophicus) o describe las funciones (Investigaciones filosóficas) del lenguaje. ${ }^{2}$ No hay más.

No obstante, a pesar de esta sentencia lapidaria de las Investigaciones filosóficas, no solo desde Wittgenstein puede hablarse de Wittgenstein; hay quienes han dicho algo sobre este autor pero no precisamente desde él, más bien desde cada quien (sobre él). Es el caso de los autores que se estudiarán a continuación. De esta manera, este artículo y los textos que a continuación examinaré sí pueden llegar a tener algún sentido (aunque no desde la concepción de sentido que Wittgenstein planteó).

\section{La interpretación antropológica y etnológica}

La interpretación antropológica y etnológica es la interpretación que surge, principalmente, a raíz de la propuesta que hizo Hacker en su ensayo «Wittgenstein's anthropological and ethnological approach» (2010), incluido en el libro Philosophical anthropology. Wittgenstein's perspective de Jesús Padilla Gálvez (ed.). ${ }^{3}$ Esta propuesta hackereana, como se evidencia en el título, hace alusión a las cuestiones antropológicas y etnológicas que

2 Hilary Putnam escribió al respecto, «una de las dificultades que acecha al encarar este período [el segundo] de la filosofía de Wittgenstein reside en el hecho de que él se rehúsa, muy prudentemente, a afirmar cualquier tipo de tesis filosófica. Su objetivo, como él mismo aclara, es modificar nuestro punto de vista, no Formular tesis» (Putnam, 2006, p. 47).

3 Asimismo, Astrid Wagner agregó que «una de las ideas clave de la obra póstuma de Wittgenstein es que la filosofía debería asumir un enfoque etnológico ("ethnologische Betrachtungsweise"). Wittgenstein desarrolló esa idea en discusión con etnólogos, psicólogos y antropólogos como Bronislaw Malinowski, Eduard Sapir, Charles Samuel Myers, Arthur Maurice Hocart y sobre todo con el economista Piero Sraffa» (Wagner, 2011, p. 1). 
se pueden encontrar en la filosofía del segundo Wittgenstein, ${ }^{4}$ sin embargo, el mismo Hacker no se extendió ni profundizó en la necesidad de una antropología y una etnología wittgensteinianas, ${ }^{5}$ su discurso, no obstante, sí da pie a debates, críticas, comentarios, etc. sobre un posible enfoque wittgensteiniano más elaborado sobre una antropología y etnología propia de este autor de Cambridge.

Para Hacker (2010) este enfoque solo es un distanciamiento, un nuevo punto de vista frente a cuestiones de antropología filosófica.

The change of viewpoint makes us more receptive to the idea, which Wittgenstein advances, that the possibility of groundless verbal expression and report of experience is grammatically bound up with the behavioral criteria, including verbal expression and report, in appropriate circumstances, for other-ascription of experience (Hacker, 2010, p. 25). ${ }^{6}$

Este enfoque no era para Hacker (2010) una metodología fundamental para la edificación de una disciplina, pues, como ya se vio en el pie de página tras anterior, esta no es la tarea principal de la filosofía de Wittgenstein. Para Hacker la tarea fundamental de esta filosofía no requiere de un punto de vista antropológico o etnológico, sino de un punto de vista interno del lenguaje.

No obstante, como se puede leer en la cita anterior, la lectura conductual que se puede substraer de las Investigaciones filosóficas, además de las referencias

4 Ya que del Wittgenstein del Tractatus logico-philosophicus solo se puede percibir un enfoque lógico-formal, principalmente (Hacker, 2010).

5 Pues, como lo dijo al final de su ensayo, «the philosophical task is to disentangle the knots we have tied in the net. For that purpose, we have to describe the net and its reticulations - and that is not an ethnological task. It is a logico-grammatical one, in which familiar rules of the uses of expressions have to be carefully selected and properly marshalled in order to exhibit the sources of confusion and misunderstanding. For that we require, as it were, an "internal point of view", not an ethnological or anthropological one» (Hacker, 2010, pp. 31-32). [«El deber filosófico es desanudar los nudos que hemos tejido en la red. Para ese propósito, tenemos que describir la red y sus "reticulaciones", y esto no es un deber etnológico. Es un deber lógico-gramatical, en el cual las reglas familiares de los usos de expresiones tienen que ser cuidadosamente seleccionadas y propiamente organizadas para exhibir las fuentes de confusión y malentendidos. Para esto requerimos, como si lo hubiera, un "punto de vista interno", no uno etnológico o uno antropológico (traducción del autor)]. Esto no se diferencia mucho de lo que se dijo de Wittgenstein, «para Wittgenstein, en última instancia, no hay más que una pluralidad de juegos lingüísticos que son inconmensurables entre sí y que un juego lingüístico no cabe ser descrito desde el punto de vista de una objetividad externa, sino desde el interior del propio juego lingüístico» (Gaillard, 2005, p. 2).

6 «El cambio de punto de vista nos hace más receptivos a una idea, la cual Wittgenstein promueve, que la posibilidad de expresiones verbales sin fundamento y el reporte de la experiencia están gramaticalmente atados al criterio conductual, incluyendo expresión verbal y reporte, en circunstancias apropiadas, por la adscripción de la experiencia del otro» (traducción del autor). 
y argumentaciones de estudios antropológicos y etnológicos que existen en esta obra, pueden ser esenciales para rastrear una posible interpretación antropológica y etnológica de la filosofía de este autor. Algunas de estas referencias y argumentaciones se pueden encontrar primero en las notas 6, 200, 282, 385 y 419 de las Investigaciones filosóficas (1988), las cuales hacen referencia a «otras tribus»; segundo, en las interpretaciones que puedan surgir sobre la propuesta de los juegos del lenguaje y las formas de vida; y, por último, en las Observaciones a La rama dorada de Frazer (Wittgenstein, 1992), principalmente a sus observaciones en torno a la evolución del comportamiento humano (desde el hombre primitivo hasta el hombre moderno ${ }^{7}$ ) y a sus observaciones críticas sobre la jerarquización de culturas, el progreso como avance del conocimiento y la incomprensión y desmérito de prácticas humanas diferentes a las avaladas por una cierta racionalidad moderna - la de Inglaterra — que Frazer consideró que estaba en la cúspide de la evolución humana. ${ }^{8}$

Estas argumentaciones en las notas y en las Observaciones a La rama dorada de Frazer, según Padilla Gálvez, son tan sutiles que promueven múltiples lecturas, entre las cuales se puede mencionar las recogidas en su libro Philosophical anthropology. Wittgenstein perspective (2010), primordialmente expuestas por Tomasini y Jacorzynski, entre otros. Asimismo, la autora Magdalena Holguín, por ejemplo, justificó el enfoque antropológico y etnológico amparándose en la idea de los juegos del lenguaje como una creación cultural en el libro Antropología de Wittgenstein. Reflexionando con P.M.S. Hacker también de Padilla Gálvez (editor y coautor):

El uso que hacemos los seres humanos de las palabras como parte de nuestras actividades, los juegos de lenguaje en los que participamos, puede considerarse como un hecho antropológico de la historia natural del hombre. En consecuencia, los conceptos serían considerados creaciones humanas (Holguín, 2011, p. 13).

7 Al respecto se puede citar lo siguiente: «Se podría comenzar un libro de antropología de esta manera: si se contempla la vida y el comportamiento del hombre sobre la tierra...» (Wittgenstein, 1992, p. 62).

8 Tomasini, a partir de las Observaciones a La rama dorada de Frazer, escribió: «No solo Frazer es ciego para comprender seres humanos del pasado, sino que dicha incomprensión radical lo imposibilita para comprenderse a sí mismo. Por ejemplo, un individuo de nuestros días instruido a la Frazer puede horrorizarse ante la descripción de un rito que culmina en la muerte de un hombre, pero podría no sentir nada especial si las fuerzas armadas de su país bombardean una ciudad "enemiga"» (Tomasini, 2010, p. 3). 
A su vez, Tomasini escribió:

La plataforma sobre la cual se desarrolla la concepción wittgensteniana del Hombre es naturalmente el lenguaje (...) la peculiar perspectiva del lenguaje adoptada por Wittgenstein, esto es, la perspectiva de los juegos del lenguaje y las formas de vida, hace del lenguaje el eje que permite dar cuenta de dos cosas: el pensamiento y la acción. Así entendida, la antropología filosófica de Wittgenstein es la concepción del Hombre como ser esencialmente lingǘstico y, por ende, racional y práctico (2011, pp. 5-6).

Jacorzynski (2011), por su lado, afirmó que los principios metodológicos expuestos en la obra de Wittgenstein, como por ejemplo los principios del análisis gramatical, del contexto, del perspectivismo, de la representación perspicua, del antiesencialismo, entre otros, son aspectos wittgensteinianos que representan una opción nueva, innovadora y consistente para realizar estudios sociales y antropológicos.

En fin, la interpretación hackereana, que ha dado mucho de que hablar, se deriva de las observaciones a las Investigaciones filosóficas, en cuanto a la descripción de los usos lingüísticos, principalmente. Wittgenstein (1988) afirmó que la filosofía debe renunciar a la explicación y quedarse en la descripción de los usos del lenguaje y, en esa medida, quedarse con la descripción de las formas de vida asociadas a estos usos. Es por esto que, desde esta metodología (descriptiva) wittgensteniana, sería posible un estudio etnológico y antropológico.

Por otro lado, quiero citar, fuera del compilado de Padilla (2010 y 2011) y de la influencia de Hacker en torno al enfoque antropológico de este, a Clifford Geertz, antropólogo estadounidense que afirmó ser un seguidor e intérprete de Wittgenstein, principalmente intérprete de las cuestiones del lenguaje privado, los juegos del lenguaje, las formas de vida, etc., como cuestiones antropológicas, y no solamente como cuestiones lingüístico-pragmáticas o de referencia al lenguaje y a la filosofía.

Geertz, citado en Anrubia (2005), escribió:

El ataque de Wittgenstein a la idea de un lenguaje privado, que condujo al pensamiento desde la gruta de la cabeza a la esfera pública donde podía ser observado, su noción de juego del lenguaje, que proporcionaba una nueva 
manera de considerarlo una vez entendido como un conjunto de prácticas, y su propuesta de «formas de vida» como el complejo de circunstancias naturales y culturales que son presupuestas en cualquier comprensión particular del mundo, parecían hechos a la medida para facilitar el tipo de estudio antropológico que yo, y otros como yo, practicamos. Es cierto que no estaban diseñados para eso, ni tampoco otras ideas contiguas y sus corolarios — «seguir una regla», «no preguntes por el significado, pregunta por el uso», «toda una nube de filosofía condensada en una gota de gramática», «decir y mostrar», «aires de familia», «estar cautivos de una imagen», «ver cómo», «vuelta al terreno áspero», «ciego por un aspecto»— sino que era parte de una despiadada y demoledora crítica de la filosofía (p. 240).

Geertz interpretó estos conceptos wittgensteinianos, que usualmente se interpretan como filosóficos, como conceptos de utilidad para ser aplicados en la formulación de una antropología (que en el caso de Geertz es una antropología cultural). Así, «el significado es su uso» Geertz lo interpretó como «la vida del símbolo es su uso»; las «formas de vida como juegos del lenguaje» las interpretó como la «cultura y comportamiento social»; y «la imposibilidad del lenguaje privado» la interpretó como «cultura colectiva, pública y simbólica que es heredada y habitada» (Anrubia, 2005). Este caso, así como los anteriormente mencionados (exceptuando, a pesar del debate que produjo, a Hacker), evidencia claramente que puede haber una interpretación antropológica de la filosofía de Wittgenstein.

\section{La interpretación pragmatista}

Putnam fue un representante fundamental para esta interpretación, sin embargo, sobre el hecho de afirmar que Wittgenstein era pragmatista Rorty fue más puntual que Putnam, ya que en su libro La filosofía y el espejo de la naturaleza (1995) afirmó que Wittgenstein era un pragmatista, ${ }^{9}$ mientras que Putnam, quien acusó a Rorty de relativista, ${ }^{10}$ no lo veía así en su totalidad. Cabe dudar de esto inclusive desde el segundo capítulo de su libro

9 «Los tratamientos del conocimiento holistas, antifundacionalista y pragmatistas que encontramos en Dewey, Wittgenstein (...) abandonan la búsqueda de conmensuración y por tanto son relativistas» (Rorty, 1995, p. 289).

10 «Por cierto que Putnam encuentra las ideas de ambos autores [Dewey y Wittgenstein] distorsionadas en la propuesta pragmatista rival de Rorty. Éste, apunta Putnam en una de sus críticas más fuertes a su compatriota, no puede aportar algo, en razón de su radical relativismo» (Rosales, 2005, p. 136). 
El pragmatismo. Un debate abierto (2006), pues este se formula a manera de pregunta «iWittgenstein era un pragmático?». Además, desde la introducción, Putnam (2006) afirmó que Wittgenstein tenía una marcada afinidad con el pragmatismo norteamericano, pero que el propio Wittgenstein no estuvo dispuesto a dejarse clasificar como pragmatista. ${ }^{11}$

Putnam no estaba interpretando a nuestro autor como un pragmatista al estilo norteamericano ni como un epistemólogo puro al estilo de Kant. ${ }^{12}$ Lo que parece destacar, siguiendo al Kant de la razón práctica, es la primacía de la moral, elemento que considera pragmático: «Otra faceta del pensamiento de Kant, un aspecto que se conecta inmediatamente con el pragmatismo, es la primacía de la razón práctica» (Putnam, 2006, p. 64).

Putnam consideraba que la filosofía de Wittgenstein, así como la de Kant, tenía una intención moral:

Quizá pueda parecer extraño afirmar que la filosofía de Wittgenstein tiene también una intención moral, especialmente desde el momento en que, con mucha frecuencia, no se la considera más que una terapia indiferente, generada por la aversión hacia la filosofía teórica. Sin embargo, quiero concluir sosteniendo precisamente que la filosofía de Wittgenstein tiene también una intención moralizadora y que muestra, por un camino distinto, el mismo tema: la primacía de la razón práctica, enunciada por la filosofía de Kant, aunque desde una particular perspectiva de redimensionamiento (Putnam, 2006, p. 67).

11 «En uno de los pasajes más paradójicos de sus reflexiones Sobre la certeza, Ludwig Wittgenstein afirma que rechaza las ideas del pragmatismo pues éste no es más que otra Weltanschauung [ideología], una mera concepción más del mundo; algo, por lo tanto, que casaría bastante mal con su proyecto filosófico, siempre desconfiado ante toda concepción metafísica» (Quintanilla, 2010, p. 276).

12 En cuanto a esto último, se puede transcribir la cita de Wischin: «Para Wittgenstein la filosofía es una reacción ante una perplejidad muy personal y su tarea consiste en hacer que esta perplejidad se disuelva. El objetivo del trabajo minucioso con los juegos de lenguaje es este: hacer que nos demos cuenta del sentido de lo que decimos y convencernos así de que hemos sido engañados por una apariencia de sentido. Es un darse cuenta no discursivo: los juegos de lenguaje, puestos uno al lado del otro, muestran cómo funciona el lenguaje, semejante a como un mosaico muestra una imagen mediante las miles de piezas de las que se compone. Esta labor detallada (...) termina por derrumbar la epistemología, disolver las paradojas, y hacer pedazos a las imágenes tradicionales como la certeza de la percepción inmediata, la distinción entre interior y exterior, la disputa entre realismo, idealismo, materialismo, empirismo y cuántos -ismos filosóficos se quieran considerar. Wittgenstein ataca también el instinto siempre presente en la filosofía de generalizar y sobre todo la tendencia de formar hipótesis y teorías a partir de estas generalizaciones; no se puede generalizar a partir de lo que muestran los mosaicos de los juegos de lenguaje» (Wischin, 2008, pp. 6-7). 
Es por esto que Putnam en el último apartado del capítulo sobre Wittgenstein de su libro El pragmatismo. Un debate abierto termina con el título El fin ético de la filosofía del último Wittgenstein. En el cual el autor señaló lo siguiente:

La recusación de la metafísica por parte de Wittgenstein es una recusación moral. Las imágenes metafísicas, según él, son perjudiciales para nosotros. El problema, ese problema que debemos enfrentar repetidamente, es saber si una forma de vida tiene un valor práctico o espiritual (...) Esta da, sin duda, la impresión de ser una posición pragmática, pero no es ese pragmatismo imaginario (detestado por los verdaderos pragmáticos) que afirma: «Es verdadero (para ti) si es bueno para ti». En realidad se encuentra mucho más cerca de la actitud de Dewey... (Putnam, 2006, p. 74).

De ahí que Putnam concluyera este capítulo sobre Wittgenstein afirmando que:

A pesar de que Wittgenstein no era, en sentido estricto, ni un «pragmático» ni un «kantiano», comparte con el pragmatismo una cierta herencia kantiana (que hasta William James fue extremadamente reacio a reconocer), y también comparte con él un (quizás el) concepto central: el concepto de la primacía de la práctica (Putnam, 2006, p. 75).

Es así como se puede resumir la interpretación, no tan pragmatista, de Putnam sobre Wittgenstein, no obstante, pragmatista al fin, por las relaciones que Putnam (2006) tejió entre Wittgenstein y pragmatistas (norteamericanos) sólidos como Pierce, James y Dewey, los cuales (incluyendo a Wittgenstein y otros más) han sido más concretamente interpretados como pragmatistas por Rorty que por Putnam. Sin embargo, la interpretación de Rorty, para Putnam, es sumamente relativista y antifundacionalista; este último, como filósofo de la ciencia y de la mente, no veía a autores como Rorty tan viables ni confiables para interpretar la filosofía de nuestro autor vienés.

Putnam no es unívocamente un filósofo pragmático, sino también un filósofo de la ciencia con una fuerte herencia de filosofía de la mente (ambas posturas completamente incompatibles con el pensamiento de Wittgenstein); pienso 
que su inclinación a favor de la epistemología representa un reducto de la modernidad contrario a la actitud general de los pragmatistas, y le impide a Putnam considerar en serio una filosofía «sin teorías» como la de Wittgenstein (Wischin, 2008, pp. 6-7).

Por otro lado, autores como Quintanilla Paz (2010) analizaron el rechazo wittgensteiniano de la pragmática como disciplina cercana a su segunda filosofía, y afirmaron la presencia evidente de otros elementos pragmáticos, aparte de los éticos (Putnam), en la segunda filosofía de Wittgenstein. Para Quintanilla, el papel central de la acción en la interpretación de las reglas es un fuerte elemento pragmático que Wittgenstein no reconoció, pero que no puede enmarcarse en otro campo más que en el de la pragmática.

Para Quintanilla (2010), el pragmatismo que Wittgenstein despreció es el pragmatismo estereotipado, el cual se basa en la idea de utilidad como criterio justificatorio de lo verdadero o de lo correcto. Mientras existe otro pragmatismo que, según este autor, Wittgenstein no reconoció, pero al cual se debe. Este último es el pragmatismo de acciones o prácticas. Quintanilla indicó: «El pragmatismo que se viene defendiendo aquí sustenta la idea de que a la normatividad le subyacen acciones o prácticas, tò prãgma, no que le subyagan meras utilidades interesadas» (Quintanilla, 2010, p. 282).

Este pragmatismo de acciones o prácticas que Quintanilla le atribuyó a Wittgenstein lo tomó del problema de seguir reglas que nuestro autor vienés propuso en las Investigaciones filosóficas. La utilidad o lo útil de una norma no le da vigencia a esa norma, ni mucho menos le da una intelección. Lo que le da vigencia es ser utilizada, «no necesitamos la verdad ni la utilidad para explicar o entender la práctica» (Quintanilla, 2010, p. 284). La práctica pública constante de una regla es una acción sin fundamentos que le da actualidad y vigencia a la regla.

Esto ya lo había planteado Wittgenstein como solución a la paradoja de la nota 201, sin embargo, nunca afirmó explícitamente que esta solución fuera pragmática. 


\section{La interpretación hermenéutica}

Como ya se mencionó en el marco teórico, esta interpretación tiene su principal representante en Richard Rorty, quien no solo aplicó esta forma de interpretar a Wittgenstein en su libro La filosofía y el espejo de la naturaleza, sino que dio pie para que cualquier otro autor aplicara este tipo de lectura sobre algún tema en general o sobre algún tema de la filosofía wittgensteniana. Y es que al ser esta interpretación una cuestión de conversación y acuerdos, más que una cuestión de fundamentos epistemológicos u objetivos, prácticamente cualquier osado escritor conocedor de la filosofía de Wittgenstein podría, desde esta interpretación, decir algo «anormal» sobre la filosofía wittgensteiniana, algo no precisamente objetivo, exacto o epistemológicamente fundante.

Rorty no tenía una manera sistemática y estructural para plantear esta forma de hacer conocimiento, lo que sí está claro es su contra hacia esa manera sistemática, estructural y fundante que se ha venido practicando como manera de hacer conocimiento, a la cual Rorty llamó filosofía, mientras que a su práctica la llamó postfilosofía. «Rorty, obviamente, no tiene consejos o recetas que dar sobre el momento de la conversación y de la sabiduría práctica, que considera como el contexto natural para una actividad y una práctica postfilosófica» (Abbagnano, 2004, p. 952).

Para esta interpretación lo importante no es fundar conocimientos (Kant) claros y distintos (Descartes), lo más importante es entrar en conversación, en este caso con Wittgenstein, o sea, decir algo del autor sin la intención de construir un conocimiento fundacional ni Verdadero.

El término «Hermenéutica» utilizado en este sentido, lo extrapola Rorty de la obra Truth and Method de Hans-Georg Gadamer quien establece claramente que la Hermenéutica no es un método para hallar la verdad que se adapte a la imagen clásica del hombre.

Gadamer postula que (...) la manera de decir las cosas es más importante que la posesión de verdades (Ávila, 2002, p. 7).

Para Rorty la epistemología tradicional busca aportes «conmensurables», es decir, aportes que puedan ser sometidos a un conjunto de reglas comunes (un fundamento común como el de la lógica, la ciencia dura o la matemática) que 
validen el hecho de ser verdaderos o falsos aportes al conocimiento. Pero la «epistemología» de Rorty (su hermenéutica) no se engarza en la epistemología tradicional, para él los aportes al conocimiento no deben estar necesariamente fundamentados en una racionalidad común, universal o exacta, sino más bien en una racionalidad propia, con un paradigma propio.

En su libro El giro lingüístico (1967) Rorty se alejó de la filosofía analítica, argumentando que esta había cambiado el fundamento de la filosofía tradicional, mientras que la filosofía tradicional había centrado su fundamento, su centro, en la epistemología, ahora la filosofía estaba cambiando este centro, ya no a una teoría del conocimiento, sino a una filosofía del lenguaje. Esto hizo que Rorty se distanciara de la filosofía analítica y buscara hacer una filosofía antifundacionalista, la cual creía haber encontrado en la hermenéutica, la pragmática y en los estudios de las nuevas perspectivas filosóficas de autores como Dewey, Quine, el segundo Wittgenstein, etc. (Rorty, 1995).

Para Rorty (1995), Dewey, Wittgenstein, Quine, Sellars y Davidson dejaron de lado la idea de conmensuración y se ubicaron más que todo en el terreno antifundacionalista y pragmatista, pues abordaron el tema del conocimiento desde la óptica holista. Para Rorty estos pensadores eran ante todo «relativistas», ya que sus teorías holistas visibilizan la posibilidad de construir un mundo propio de conocimientos.

Este pasaje y los anteriores, más el hecho de que Wittgenstein renunció a la explicación y la defensa de la descripción como único método de la filosofía, revelan la posibilidad de una interpretación hermenéutica que fue defendida por Rorty sobre el Wittgenstein de las Investigaciones filosóficas. Además, para Rorty, Wittgenstein no estaba aceptando un fundamento epistemológico común (como sí lo pudo hacer en el Tractatus logico-philosophicus), sino más bien creando sus propias reglas, con su propio fundamento.

Al respecto, Abbagnano indicó que el Wittgenstein de Rorty

Buscó una nueva vía «fundacional» para la filosofía, y solamente abandonó estos intentos cuando encontró la vía justa, la que lleva fuera de la filosofía fundacional y epistemológica: se liberó de la concepción kantiana de la filosofía como fundante y dedicó su propio tiempo a ponernos en guardia contra aquellas tentaciones a las cuales él mismo había cedido (...) su obra posterior es terapéutica y edificante, más que sistemática, e inclina a hacer 
reflexionar al lector sobre los motivos que tiene para filosofar, más que a presentarle un nuevo programa filosófico (2004, p. 950).

Una interpretación muy similar, expuesta el mismo año que La filosofía y el espejo de la naturaleza, se puede encontrar en el libro La condición postmoderna de Jean-François Lyotard. ${ }^{13}$

Lyotard (2000) planteó en su libro La condición postmoderna (publicado por primera vez en 1979) que la ciencia y la filosofía de la modernidad habían fracasado en legitimar sus propias verdades (a través de metarrelatos), por lo que un saber, que él llamó postmoderno — basado más en una pragmática de partículas lingüísticas, de discursos inconmensurables, sensible ante las diferencias, sin dicotomías falso/verdadero, etc.—, era más útil para legitimar los relatos. ${ }^{14}$

Con respecto a Wittgenstein (el segundo), Lyotard lo interpretó, a raíz de su propuesta de los juegos del lenguaje, como un pesimista de la modernidad, que ha contribuido con la deslegitimación de la ciencia y los metarrelatos. Lo cual evidencia una interpretación postmoderna sobre este autor vienés.

Esta «deslegitimación» [la de los juegos del lenguaje] abre el camino a una importante corriente de la postmodernidad: la ciencia juega su propio juego, no puede legitimar a los demás juegos de lenguaje. Por ejemplo, el de la prescripción se le escapa. Pero ante todo no puede legitimarse en sí misma como suponía la especulación (Lyotard, 2000, pp. 76-77).

En fin, esta interpretación postmoderna, que se incluye dentro de la hermenéutica por su similitud, consiste en interpretar y, por ende, utilizar

13 Similar por las coincidencias entre el proyecto del postmodernismo y el de la hermenéutica de Rorty. Estas coincidencias son el antiesencialismo, el antifundacionalismo, el descrédito de la noción clásica de verdad, razón, estructuras, objetividad, etc.

14 «Se tiene por "postmoderna" la incredulidad con respecto a los metarrelatos. Ésta es, sin duda, un efecto del progreso de las ciencias; pero ese progreso, a su vez, la presupone. Al desuso del dispositivo metanarrativo de legitimación corresponde especialmente la crisis de la filosofía metafísica, y la de la institución universitaria que dependía de ella. La función narrativa pierde sus functores, el gran héroe, los grandes peligros, los grandes periplos y el gran propósito. Se dispersa en nubes de elementos lingüísticos narrativos, etc., cada uno de ellos vehiculando consigo valencias pragmáticas sui generis. Cada uno de nosotros vive en la encrucijada de muchas de ellas. No formamos combinaciones lingüísticas necesariamente estables, y las propiedades de las que formamos no son necesariamente comunicables. Así, la sociedad que viene parte menos de una antropología newtoniana (como el estructuralismo o la teoría de sistemas) y más de una pragmática de las partículas lingüísticas. Hay muchos juegos de lenguaje diferentes, es la heterogeneidad de los elementos. Sólo dan lugar a una institución por capas, es el determinismo local» (Lyotard, 2000, p. 10). 
la propuesta de los juegos del lenguaje como «fundamento» legítimo de los relatos científicos, filosóficos, cotidianos, etc., esto con el principal objetivo de mostrar que cada juego del lenguaje tiene sus propias reglas y sus propios consensos, lo cual, según Lyotard, acaba con los relatos universalistas que pretenden homogenizar a la sociedad. Esto último era del conocimiento de Lyotard, quien estaba consciente de que su interpretación podría conllevar a una sociedad heterogénea, pero más justa.

\section{La interpretación escéptica}

Esta interpretación nació a raíz de las nociones escépticas que Kripke describió de las Investigaciones filosóficas de Wittgenstein, principalmente de las notas y las argumentaciones en torno a lo que Wittgenstein planteó sobre el lenguaje privado y el problema de seguir una regla. ${ }^{15}$ Esto lo hizo Kripke en su obra Wittgenstein a propósito de reglas y lenguaje privado: una exposición elemental (2006).

Lo que Kripke (2006) concluyó a partir de lo descrito sobre la segunda filosofía de Wittgenstein es que no hay forma de justificar semánticamente una regla y su aplicación. Lo cual deja en evidencia, según Kripke, una paradoja insalvable para nuestro autor de Cambridge. ${ }^{16}$

15 Se dejó esta interpretación para el final debido a que es la lectura en la que más se encontró discusiones, réplicas, estudios, etc., por lo que será, como se va a poder ver, la que cuente con el mayor tratamiento y análisis de todas las interpretaciones expuestas.

16 «Pero al final no se puede soslayar el problema escéptico, y surge precisamente con la cuestión de cómo la existencia en mi mente de una entidad mental o idea puede constituir el captar un sentido particular en lugar de otro. La idea en mi mente es un objeto finito (...) puede que haya otra idea en mi mente, que se suponga que constituye su acto de asignar una interpretación particular a la primera idea; pero entonces, obviamente, el problema surge de nuevo a este nivel (una regla para interpretar una regla otra vez). Y así sucesivamente. Para Wittgenstein, el platonismo es en gran medida una inútil evasión del problema de cómo nuestras mentes finitas pueden dar reglas que se supone que se aplican a una infinidad de casos. Los objetos platónicos puede que sean autointerpretativos, o mejor, puede que no necesiten interpretación; pero al final debe haber envuelta alguna entidad mental que hace surgir el problema escéptico» (Kripke, 2006, p. 67). Por otro lado, Gustavo Martín escribió lo que podría ser una réplica a la paradoja insistente de Kripke: «Wittgenstein refiere la importancia que tiene el uso en la determinación del significado de la regla (...) señala la importancia de no considerar como posibilidad una regresión ad infinitum de reglas (...) Sin embargo, si intentamos comprender lo que quiere expresar Wittgenstein pienso que nos encontramos con que, en primer lugar, para jugar un juego hay que respetar sus reglas, aun cuando no las comprendamos a cabalidad o estemos en desacuerdo con ellas, y, en segundo término, estas reglas no tienen un fundamento último que las explique y al cual puedan ser reducidas» (Martín, 2006, p. 144), por lo tanto no requieren justificación, lo cual podría acabar con la paradoja acusada por el escéptico imaginario de Kripke. 
Pero es momento de repasar la paradoja de la nota 201 de las Investigaciones filosóficas de Wittgenstein y la solución que este dio en notas posteriores.

[Nota 201] Nuestra paradoja era ésta: una regla no podía determinar ningún curso de acción porque todo curso de acción puede hacerse concordar con la regla. La respuesta era: Si todo puede hacerse concordar con la regla, entonces también puede hacerse discordar. De donde no habría ni concordancia ni desacuerdo.

Que hay ahí un malentendido se muestra ya en que en este curso de pensamientos damos interpretación tras interpretación; como si cada una nos contentase al menos por un momento, hasta que pensamos en una interpretación que está aún detrás de ella. Con ello mostramos que hay una captación de una regla que no es una interpretación, sino que se manifiesta, de caso en caso de aplicación, en lo que llamamos «seguir la regla» y en lo que llamamos «contravenirla».

De ahí que exista una inclinación a decir: toda acción de acuerdo con la regla es una interpretación. Pero solamente debe llamarse «interpretación» a esto: sustituir una expresión de la regla por otra.

202. Por tanto «seguir la regla» es una práctica. Y creer seguir la regla no es seguir la regla. Y por tanto no se puede seguir «privadamente» la regla, porque de lo contrario creer seguir la regla sería lo mismo que seguir la regla (Wittgenstein, 1988).

Algunos han llamado a esta solución «interpretacionismo de tercera persona» (Mota, citado por Fuentes, 2010, p. 95) o convencionalismo pragmático (lingüístico). ${ }^{17}$ Kripke (2006), por su lado, la describió como

17 «La solución escéptica que da Wittgenstein a la paradoja escéptica plantea que no existen "condiciones de verdad", como tampoco hay "hechos que se correspondan", sino un uso adecuado o inadecuado de las aserciones. El grado de verdad siempre va a depender de la atribución que en este sentido se haga dentro de los juegos de lenguaje y no de algún a priori o de la existencia de un principio o fundamento. Tanto la verdad como el significado dependen de reglas determinadas por los acuerdos intersubjetivos que se encuentran detrás de los juegos de lenguaje. Por ello, no existen reglas privadas, como tampoco lenguaje o significados privados. Por lo mismo, la solución que Wittgenstein plantea es la existencia de un juego en el que ocurre una atribución a los otros de los conceptos. De esta manera, cada uno tiene la posibilidad de evaluar si los otros hacen un uso adecuado o no de los conceptos. Ella supone, por lo mismo, tres conceptos claves: el consenso, la forma de vida y los criterios (...) La propuesta de Wittgenstein como bien lo afirma Kripke se orienta hacia las "condiciones de la asertabilidad"; es decir, se refieren a un acuerdo logrado para obtener cierto tipo de respuestas y otorgar un significado determinado de forma tal que nadie pueda sentirse autorizado para considerar a esas respuestas y a ese significado como erróneos» (Martín, 2006, pp. 159 -160). 
una solución escéptica que deja en su exposición, tratamiento y solución un escepticismo semántico radical. Incluso él mismo consideró este escepticismo como insalvable, ante el cual, de igual forma que Wittgenstein, no le quedaba más que proponer una solución para muchos también escéptica. «Kripke propone una solución escéptica, es decir, una concepción de lo normativo que parte del reconocimiento de que el desafío del escéptico es incontestable» (Garreta, 2004, p. 3).

Con respecto a seguir una regla, se puede decir que alguien ha aprendido a seguir una regla durante la interacción con otras personas, y esta se ha quedado impresa en su memoria, pero ¿qué justifica, por el hecho de que siempre que ese alguien ha seguido la regla y aunque siempre ha logrado seguirla según esta, que esa regla siempre esté justificada? ¿Cómo es que, a partir de casos finitos en los que alguien ha seguido la regla y todo le ha salido bien, se puede justificar que infinitos casos vayan a salir bien si se sigue la misma regla ${ }^{18}$ ? Esto no se soluciona desde una perspectiva privada, o sea, pensando en una persona aislada. Primero porque no se puede imaginar a una persona que esté siempre aislada de otras, si fuera posible se podría hasta cuestionar el hecho de llamarla persona, sería más bien un ente extraño, pues no tendría ningún rasgo social. Segundo, porque si hubiera una persona que se aisló (un Robinson Crusoe, por ejemplo) y sigue reglas privadamente, solo estaría creyendo que sigue reglas, pues estas solo ocurren en su mente, pero no estaría siguiendo reglas justificadas, sino autojustificadas, lo que evidencia un problema de justificación y, como lo planteó Wittgenstein principalmente en las notas 258 y 265 de sus Investigaciones filosóficas, de criterio de corrección.

No es posible establecer un criterio de corrección utilizando «el mismo objeto» que se desea corregir. Aquí es válida la analogía del periódico que planteó Wittgenstein en la nota 265 de las Investigaciones filosóficas: «Como si alguien comprase varios ejemplares del periódico de hoy para cerciorarse de la verdad de lo escrito» (1988). Justificar privadamente una regla (o un

18 Esto recuerda el problema de la inducción humeana. La cual plantea que nunca una inducción (una cantidad de casos) puede justificar el conocimiento (total, seguro, universal o infinito) de algo. «Se concede universalmente que la capacidad del espíritu es limitada y que no puede jamás alcanzar una concepción plena y adecuada del infinito, y, aunque no se concediese, esto sería bastante evidente por la más corriente observación y experiencia (...) Al rechazar la posibilidad de una capacidad infinita del espíritu, suponemos que puede llegar a un fin en la división de sus ideas, por lo tanto, no hay modo posible de evadir la evidencia de esta conclusión» (Hume, 1923, p. 37). 
uso del lenguaje) sería como tratar de establecer la veracidad de una noticia aparecida en el periódico comprando el mismo periódico. ${ }^{19}$ No importa cuántos periódicos usemos, nunca será esto un criterio de corrección. Cada quien (siguiendo con el ejemplo de Robinson Crusoe) podría cambiar a su gusto las reglas, no habría quien, a parte de él, que confronte y juzgue el correcto o incorrecto seguimiento de estas reglas, es decir, nadie, a menos que alguien crea que él mismo lo está haciendo (un solipsista, un caso de esquizofrenia, de doble personalidad, etc.), y si fuera el caso de ser reglas fijas, no cambiadas por sí mismo, ¿cómo le llamaríamos al hecho de equivocarse cuando ese alguien no sigue un paso de sus propias reglas? ¿Se autoequivocó?20

Las reglas se entienden y tienen sentido en colectividad, por lo tanto, el problema de seguir reglas se resuelve cambiando la óptica desde donde se observa el problema, ya no desde una óptica privada, sino pública. No viendo el problema desde un agente, sino desde un grupo de ellos. «La regla, sin el respaldo de la práctica de una comunidad, no tiene consistencia normativa en absoluto, no hay significado alguno sin el hecho bruto y contingente de la concordancia en la conducta de un grupo de agentes» (Garreta, 2004, p. 29). ${ }^{21}$

Ahora, respecto a la significación de una palabra, alguien (socialmente considerado lúcido) usa una palabra (carro por ejemplo) porque ha adquirido en su pasado una imagen mental de esa palabra y al usarla concuerda con el uso lingüístico y ostensivo que otros le dan a la palabra, lo cual justifica que la ha usado bien y así se da la comunicación con los otros.

Pero qué ocurre cuando ese alguien (considerado como lúcido) utiliza palabras de sensación como dolor o de realización como suma de cantidades, esto no corresponde a ninguna imagen mental dada por el exterior de su mente, sin embargo, cuando las usa, las usa bien.

La significación interna de una palabra es una cuestión privada a la cual solo cada individuo puede tener acceso (cuestión precisamente que

19 Otros ejemplos, en relación con este tema, que Wittgenstein dio en esta misma nota (265 de las Investigaciones filosóficas) son: «Consultar una tabla en la imaginación no significa consultar esa tabla en la realidad, así como tampoco la imagen del resultado de un experimento imaginado, es el resultado de un experimento [real]». Es decir, no se puede privadamente justificar un uso del lenguaje.

20 Wittgenstein, en la nota 202, fue muy claro en este asunto: «Por tanto "seguir la regla" es una práctica [colectiva]. Y creer seguir la regla no es seguir la regla. Y por tanto no se puede seguir "privadamente" la regla» (Wittgenstein, 1988).

21 Kripke (2006) trató de solucionar esta cuestión planteando una teoría disposicional, sin embargo no logró resolver el «paso indebido» de justificar a partir de disposiciones finitas la aplicación infinita de una regla. 
Wittgenstein intentó rebatir). No hay forma de saber si cuando otros usan las palabras carro, dolor o suma, por decir algunos ejemplos, está sucediendo lo mismo en sus mentes que en las de los otros (el problema de las otras mentes y el problema del lenguaje privado).

¿Qué justifica que la imagen de carro, la sensación de dolor o la realización de una suma sea igual a la de los otros? Aquí está la solución wittgensteniana: solo su uso, un uso que concuerda con el uso de los otros.

Por lo tanto, no hay alguna regla privada, personal, que me justifique usar una palabra si no es por una práctica colectiva común (una pragmática), una regla compartida por una comunidad. ${ }^{22}$

La tesis de Kripke es que tal atribución de significado puede justificarse sólo cuando existe, o mejor dicho, preexiste, una comunidad de personas cuya utilización del símbolo «+» [por ejemplo] al realizar cálculos conduce a resultados concordantes en la gran mayoría de los casos. Estamos autorizados a atribuir el uso de una regla a otro sujeto cuando sus respuestas concuerdan con las que daría la comunidad en las mismas circunstancias (Garreta, 2004, p. 4).

Esta descripción kripkeana ha encontrado eco en Latinoamérica en autores como Rodríguez Tirado, Garreta Leclercq, Gustavo Martín y Gensollen Mendoza, entre otros, los cuales — tardíos en su reacción, aunque no más de cuatro años - han debatido y criticado esta descripción (interpretativa) de forma muy original y erudita. Sin embargo, fuera de las fronteras latinoamericanas la reacción fue casi inmediata, autores como McDowell y McGinn, entre otros, han sido igualmente duros críticos, pero a la vez buenos y precisos analistas que, junto con sus conocimientos y sus propias interpretaciones sobre Wittgenstein, llevaron las cuestiones planteadas por Kripke a direcciones no imaginadas ni comprendidas por este. Lo cual enriqueció la discusión y la postuló; el mismo Kripke (2006) lo sugirió como una problemática de gran importancia para la filosofía en general.

22 Me parece que la cuestión es lica de Costa Rica, d Caton de e(e first time. and there was a problem grades were not very low, the main problem was with Emilesta: no es posible la justificación meramente semántica del significado ni el uso privado de una palabra o regla, pero sí la justificación semántico-pragmática (colectiva) de esta. Lo cual para muchos no deja de ser una solución escéptica, pero para otros autores, como Gustavo Martín, el argumento escéptico y su solución escéptica es rebatible: «El argumento escéptico queda rebatido cuando me doy cuenta de que mis significados coinciden con los de la comunidad que comparte conmigo juegos de lenguaje y formas de vida» (Martín, 2006, p. 161). 
En cuanto al trabajo de McDowell Wittgenstein on following a rule (1984) se puede citar lo mencionado por Rodríguez Tirado: «El desacuerdo entre Kripke y McDowell estriba en que, para el segundo, Wittgenstein no acepta la paradoja enunciada en el § 201, sino, en su lugar, insiste en que hay una manera de entender una regla que no es una interpretación» $(1986$, p. 11).

Para McDowell (1984) obedecer una regla no es una interpretación, entendiendo interpretación como lo hizo Wittgenstein (1988): «Sustituir una expresión de la regla por otra» (nota 201), sino una práctica social de vida (no individual), lo cual elimina la necesidad de justificar el seguimiento de reglas por interpretación. Sin embargo, esto evidencia que 1) el seguimiento de reglas ya no se ve como el problema del sujeto aislado que necesita interpretar una regla para seguirla y 2) que al suprimir la figura del sujeto aislado se obtienen dos aspectos: se eliminan los mecanismos internos de la conciencia del sujeto y, dada la eliminación de estos mecanismos internos, solo queda la apelación externa a una práctica social que establece y dirige, no racionalmente, sino por costumbre y obediencia conductual, el seguimiento de una regla.

McGinn, por su parte, en su trabajo Wittgenstein on meaning (1984) criticó y negó tanto la interpretación de McDowell en cuanto a esta práctica social que elimina los mecanismos internos de la conciencia del sujeto como la solución kripkeana del comunitarismo (la cual no dista mucho de la noción de práctica social defendida por McDowell).

Para McGinn (1984) la justificación y el seguimiento de reglas no debe concebirse como interpretación ni como práctica social. El entendimiento, la comprensión racional (que es un mecanismo interno de la conciencia) de una palabra o regla está, principalmente, en el interior de una persona, en su entendimiento. McGinn (1984) concibió este entendimiento como un estado mental, una capacidad mental que se manifiesta en realizaciones físicas (práctica) como las que se evidencian con el empleo del lenguaje, con las cuales tenemos una base objetiva e individual para justificar el seguimiento de una regla y la significación de esta.

McGinn no negó la importancia del aspecto social del lenguaje, pero en lo que sí estuvo en desacuerdo fue en el hecho de significar o justificar lo que es seguir una regla a partir de la interpretación o de la apelación a una práctica social o comunitaria nada más. 
Existe, por tanto, un hecho «en mí» que explica que yo haya entendido, o querido expresar, la función suma con el símbolo «+», y no la función ruma; y ese hecho no es otro que la posesión de una, y sólo una, capacidad que puede atribuirse correctamente cuando (y sólo cuando) yo tenga en mente el concepto de adición y no, digamos, el concepto de cuadición. Para explicar, entonces, lo que es entender un concepto, o seguir una regla, no hace falta apelar a la comunidad; es decir, esos hechos pueden explicarse en términos individualistas, y esta concepción del entendimiento, a diferencia de lo que he llamado «la concepción comunitaria» de lo que es seguir una regla (o entender un concepto), sí salva la idea de objetividad (Rodríguez, 1986, p. 28).

\section{Conclusión}

Antes de concluir lo que fue un repaso de cuatro de las interpretaciones más destacadas y discutidas de la filosofía wittgensteiniana, voy a citar una última interpretación (la conductista) que ya se pudo vislumbrar en el ensayo de Hacker, ${ }^{23}$ la cual, a pesar de no haber sido tan destacada en algún libro, como las anteriores, cuenta con pasajes y artículos que podrían edificarla. ${ }^{24}$

No obstante, por razones de espacio, solo voy a citar algunos fragmentos de esta interpretación.

En relación con lo que puede ser una interpretación conductista, algunos autores anotaron lo siguiente: «Explicar la racionalidad y la autoridad epistémica con referencia a lo que la sociedad nos permite decir, y no lo segundo por lo primero, constituye la esencia de lo que designaré con el nombre de "conductismo epistemológico", actitud común a Wittgenstein y Dewey» (Rorty, 1995, p. 165). «La idea de que para entender una regla es necesario obedecerla más de una vez (...) obedece a esa buena dosis de conductismo que puede encontrarse en el pensamiento de Wittgenstein»

23 «Wittgenstein's anthropological and ethnological approach» incluido en el libro Philosophical anthropology. Wittgenstein`s perspective de Jesús Padilla Gálvez (ed.) (2010). En donde se plantea: «El cambio de punto de vista nos hace más receptivos a una idea, la cual Wittgenstein promueve, que la posibilidad de expresiones verbales sin fundamento y el reporte de la experiencia están gramaticalmente atados al criterio conductual, incluyendo expresión verbal y reporte, en circunstancias apropiadas, por la adscripción de la experiencia del otro» (Padilla, 2010, p. 25).

24 Edificarla en el sentido rortyano, ya que, según Rorty (1995), esta interpretación, así como las otras, solo es una cuestión de conversación que pretende edificar uno de tantos discursos posibles al margen de los discursos tradicionalmente predominantes. No se pretende crear relatos fundacionalistas (metarrelatos), pues no se trata de un discurrir epistemológicamente fundante, sino más bien, siguiendo a Rorty, un discurrir edificante. 
(Rodríguez, 1986, p. 15). «La Filosofía de la mente de Wittgenstein ha sido frecuentemente calificada de behaviorista, debido a su negativa a reconocer la "interioridad"» (Martín, 2006, p. 146).

Incluso en Costa Rica pueden encontrarse lecturas conductistas de la filosofía wittgensteiniana, entre ellas se puede citar la de Castañeda (1977) El atomismo sintáctico en la filosofía posterior de Wittgenstein, y la naturaleza de las cuestiones filosóficas ${ }^{25}$ y la de Gallardo (2011) Wittgenstein: epistemología y lenguaje. ${ }^{26}$

\section{Bibliografía}

Abbagnano, N. (2004). Diccionario de filosofía (actualizado y aumentado por Giovanni Fornero). México, D.F.: Fondo de Cultura Económica.

Anrubia, E. (2005). Rastros de la influencia wittgensteiniana en la antropología interpretativa de Clifford Geertz. Thémata, 35, 239-246.

Ávila, F. (2002). Filosofía, epistemología y hermenéutica en el pensamiento de Richard Rorty. A Parte Rei, 23. 1-13. Recuperado de http://serbal.pntic.mec.es/ cmunoz11/ inveslibre.pdf

Castañeda, H. (1977). El atomismo sintáctico en la filosofía posterior de Wittgenstein, y la naturaleza de las cuestiones filosóficas. Revista Filosofía de la Universidad de Costa Rica, XV(41), 175-186.

Fuentes, P. (2010). Sílvio Mota Pinto, escepticismo del significado y teorías de conceptos. Crítica, 42(125), 95-119.

Gallardo, A. (2011). Wittgenstein: epistemología y lenguaje. Praxis, 66, 87-97.

Garreta, M. (2004). Acerca de las consecuencias del desafío escéptico de Kripke. Ponencia presentada en las III Jornadas Wittgenstein realizadas del 2 al 4 de diciembre de 2004 en Argentina. Recuperado de http://www.accionfilosofica.com/jornadas/jornada.pl?id=2

Hacker, P. (2010). Wittgenstein's anthropological and ethnological approach. En J., Padilla (ed), Philosophical anthropology. Wittgenstein`s perspective. 15-32. Ontos Verlag, Frankfurt a. M. http://dx.doi.org/10.1515/9783110321821.15

Holguín, M. (2011). Antropología o historia natural. En J., Padilla (ed.), Antropología de Wittgenstein. Reflexionando con P.M.S. Hacker. 117-126. Madrid, España: Plaza y Valdés.

25 De la cual se puede transcribir lo siguiente: «En el texto citado [las Investigaciones filosóficas] hay un ataque contra la cognoscibilidad de mis dolores. Esto prepara el escenario tanto para un ataque contra lo privado como para el desarrollo de una doctrina conductista sobre lo mental. Pero es justo declarar enfáticamente que las Investigaciones no defienden claramente una doctrina conductista, que muchos wittgensteinianos adoptan el conductismo y hasta se lo atribuyen al maestro, pero es muy probable que en la mejor interpretación, las Investigaciones son una colección de reflexiones, unas profundas, otras superficiales, muchas de ellas tentativas, en las que se consideran puntos de vista contrarios, pero que Wittgenstein no se decidió en muchos casos por una doctrina o por otra» (Castañeda, 1977, p. 182).

26 Pues «los contenidos mentales estarían constituidos por condiciones externas que los hacen ser lo que son» (Gallardo, 2011, p. 96; parafraseando a Drestke). 
Jacorzynski, W. (2011). La filosofía de Ludwig Wittgenstein como una nueva propuesta para la antropología y las ciencias sociales. Sociológica, año 26(74), 177-204.

Lyotard, J. (2000). La condición postmoderna. Madrid, España: Cátedra.

Kripke, S. (2006). Wittgenstein a propósito de reglas y lenguaje privado: una exposición elemental. Madrid, España: Tecnos.

McDowell, J. (1984). Wittgenstein on following a rule. Synthese, 58(3) 325-363. http:// dx.doi.org/10.1007/BF00485246

McGinn, C. (1984). Wittgenstein on meaning. Blackwell: Oxford.

Martín, G. (2006). Saul Kripke y la paradoja de Wittgenstein: un ensayo de crítica del escepticismo. Episteme, 26(1), 141-162.

Putnam, H. (2006). El pragmatismo. Barcelona, España: Gedisa.

Quintanilla, M. A. (2010). ¿Era Wittgenstein pragmatista, los pragmatistas son wittgensteinianos, o ni una cosa ni la otra?: sobre reglas, verdades y acciones sociales. Daímon, suplemento 3, 275-292.

Rodríguez, A. (1986). Seguir una regla: tres interpretaciones. Crítica, 18(53), 3-32.

Rorty, R. (ed.) (1967). The Linguistic Turn: Recent Essays in Philosophical Method. Chicago and London: The University of Chicago Press.

Rorty, R. (1995). La filosofía y el espejo de la naturaleza. Madrid, España: Cátedra.

Tomasini, A. (2011). Wittgenstein: la filosofía de la antropología y antropología filosófica. Recuperado de http://www.filosoficas.unam.mx/ tomasini/ENSAYOS/Antropologia.pdf

Wischin, K. (2008). Putnam, Wittgenstein y el pragmatismo. Universidad Autónoma de Querétaro. Recuperado de http://www.reocities.com/kurt_wischin/ensayos/putnam.pdf

Wittgenstein, L. (1988). Investigaciones filosóficas. Barcelona, España: Crítica.

Wittgenstein, L. (1992). Observaciones a La rama dorada de Frazer. Madrid, España: Tecnos.

Wittgenstein, L. (1999). Tractatus logico-philosophicus. Madrid, España: Alianza. 